\title{
Depressive coping and emotional distress predicted shortened survival in patients with lung cancer
}

Faller H, Bülzebruck H, Drings P, et al. Coping, distress, and survival among patients with lung cancer. Arch Gen Psychiatry 1999 Aug;56:756-62.

QUESTION: In patients with lung cancer, do depressive coping, emotional distress, and depression predict shortened survival?

Design

Inception cohort followed up for 7-8 years after diagnosis.

Setting

A tumour centre in Heidelberg, Germany.

\section{Patients}

103 patients (mean age 59 y, 83\% men) who had been newly diagnosed with lung cancer and had not yet begun their primary treatment were recruited between June 1989 and December 1991.

\section{Assessment of prognostic factors}

Coping (active and depressive) was measured using the Freiburg Questionnaire of Coping With Illness with self report and interviewer rating formats; emotional distress was measured using a newly developed, validated clinical scale with self report and interviewer rating formats; and depression was measured by the Depression Scale with self report format. The biomedical prognostic factors considered were tumour stage, histological classification, and Karnofsky performance status. Attending physicians also rated patients on 5 point scales for severity of disease, unfavourable prognosis, and expected treatment success.

\section{Main outcome measure \\ Mortality.}

\section{Main results}

At follow up in January 1998, 92 patients (89\%) had died. Survival prediction using Kaplan-Meier analysis with psychological scales dichotomised at the median showed that patients with high scores for self reported depressive coping and interviewer rated emotional distress had shorter survival than patients with low values (9 $v 14 \mathrm{mo}, \mathrm{p}=0.007$ and $9 \approx 15 \mathrm{mo}, \mathrm{p}=0.02$, respectively). Tumour stage $(\mathrm{p}=0.002)$, histological cell type $(\mathrm{p}=0.01)$, and Karnofsky performance status $(\mathrm{p}<0.001)$ were related to survival time as were physicians' ratings of disease severity $(\mathrm{p}=0.02)$. Physicians' ratings of unfavourable prognosis $(p=0.07)$ and treatment success $(\mathrm{p}=0.54)$ and patients' age $(\mathrm{p}=0.72)$ and sex $(p=0.91)$ were not related to survival time. The predictors that had a statistically significant effect on survival were entered into a Cox proportional hazards regression model. Self report of depressive coping, interviewer rating of emotional distress, tumour stage, and Karnofsky performance status were independent predictors of survival $(\mathrm{p} \leqslant 0.04)$. When the interaction of cell type and tumour stage were included, self reported depressive coping, interviewer rated emotional distress, and Karnofsky performance status were still significantly related to survival $(\mathrm{p} \leqslant 0.02)$. These also remained significant after adjustment for physician rating of severity of disease $(p \leqslant 0.04)$.

\section{Conclusion}

In patients with lung cancer, patient self reported depressive coping and interviewer rated emotional distress predicted shortened survival and remained as significant survival predictors after adjustment for biomedical risk factors.

\section{COMMENTARY}

Linking survival to psychological state is a contentious issue in cancer care. At one end of the spectrum, various "positive" emotional states are held to have a benign and potentially curative influence on outcome. At the other end are those for whom such ideas are anathema and dangerous. In this debate sound data are sparse. Faller et al's study goes some way to redressing this lacuna. The participants in this study had lung cancer-an unusual group in this area of research, often ignored perhaps because of the relatively poor prognosis of this type of cancer. Various measures, both psychometric and structured interview, were used, and although these may be relatively unfamiliar to non-German readers, they seem to cover much the same issues as more widely used measures. One common criticism of research in this area is that biomedical variables are not taken into account. No such criticism can be levelled at this study and the analyses used multiple covariates.

The key finding was that a depressive coping style and interviewer rated distress were both significantly associated with reduced survival times in conjunction with tumour stage and general physical state (performance status). This is an important finding and one that has been noted in women with breast cancer. ${ }^{1}$ What may be equally important, and of great clinical importance, is that in neither report was there any suggestion of influence in the other direction-that is, a non-depressive coping style (in Watson et al's terminology "fighting spirit") enhancing survival. Patients may be told-with the best possible motives-to "think positive" as this will help them to survive the cancer. This is often an additional burden for people who are already struggling with a lethal disease and extremely burdensome treatments. Patients often report feelings of self recriminating blame for "letting people down," or that they are censoring expressions of sadness or fear because this is seen as not being positive enough. The message from both these reports is that we should be focusing our clinical efforts on helping patients to deal with their depression and to develop their antidepressogenic coping skills.

Peter Harvey, PhD The Cancer Centre University Hospital Birmingham NHS Trust Birmingham, $U K$

1 Watson M, Haviland JS, Greer S, et al. Influence of psychological response on survival in breast cancer: a population-based cohort study. Lancet 1999;354:1331-6. 